\title{
O heroísmo impossível dos suicidas: um estudo das motivações de Werther
}

Felipe Vale da Silva ${ }^{1}$

Sabrine Ferreira da Costa ${ }^{2}$

\section{Resumo}

Os Sofrimentos do jovem Werther (1774) de Goethe foi pioneiro em retratar o declínio de um jovem suicida em chave não moralista. O livro foi recebido como uma apologia ao suicídio e supostamente influenciou alguns leitores a tirarem a própria vida. Analisaremos como tal resolução vai contra a mensagem de fundo da obra, retomando, por meio de close reading, cenas centrais em que o tema é discutido por suas personagens. Em vez de um ato heroico, o suicídio é fruto de uma polarização do ego e compreensão filosófica do homem como um ser nãosocial que, para Goethe, é sintoma do individualismo de sua época.

Palavras-chave: Goethe. Suicidio. Efeito Werther. Sturm und Drang

\footnotetext{
${ }^{1}$ Doutor em Letras Português-Alemão pela Universidade de São Paulo.

${ }^{2}$ Graduanda em Letras Francês pela Universidade de São Paulo.
} 
"Mas, no final, é preciso mais coragem para viver do que para se matar." - Albert Camus

Em 1974, o sociólogo David Phillips introduziu o conceito Werther effect à comunidade científica definindo-o como o fenômeno ocorrido há duzentos anos em que leitores do famoso romance de Goethe, ao lerem que seu protagonista comete suicídio, são influenciadas a tomar a mesma atitude desesperada. "Nunca se comprovou conclusivamente [que houve] amplas imitações do suicídio de Werther, mas autoridades ficaram apreensivas o bastante para banir o livro em diversas áreas, incluindo na Itália, Leipzig e Copenhagen” (PHILLIPS, 1974, p. 340) ${ }^{3}$. O argumento de seu artigo, em vez de tratar detidamente de Goethe ou de sua época, decorreu de um levantamento curioso: nele, Phillips comparava o momento em que suicídios de celebridades eram divulgados no New York Times com estatísticas oficiais de morte autoinfligida em meio à população civil. Após analisar trinta e três casos ocorridos entre 1947 e 1967, foi possível observar um padrão. Por algum motivo, a morte de um famoso parecia encorajar significativamente demais óbitos de pacientes de depressão e outros distúrbios. Isto é dizer: se a premissa de Phillips estivesse certa, a morte de um desconhecido poderia influenciar um indivíduo a tirar a própria vida até mais do que a morte de um parente próximo. E mais: cada caso favorecia o suicídio em um grupo específico; o aparente suicídio de Marilyn Monroe, o que gerou mais casos de suicídios por imitação (copycat suicides) no recorte de tempo estudado pelo sociólogo, parecia afetar mais mulheres na faixa dos trinta anos e que, por extensão, cresceram tendo a atriz como um modelo de beleza e feminilidade (DEVITTT, 2017). Para complicar ainda mais o caso, Phillips chegou a sugerir que havia incidência do suicídio de personagens fictícias de telenovelas em casos reais, ainda que não tivesse dados rigorosos o bastante para suportar uma tal tese (KUNCZIK; ZIPFEL, 2006, p. 94).

Estudiosos de diversas áreas, e mesmo instituições midiáticas, passaram a contestar ou apoiar a curiosa tese, e hoje ela é um termo técnico amplamente divulgado entre leigos. É um truísmo dizê-lo, mas poucos artigos de sociologia causam tamanho interesse popular, e um rebuliço em torno do tema do "suicídio por influência" é, na verdade, um fenômeno muito mais antigo e conhecido por quem estuda literatura. Consideremos o primeiro romance de Johann Wolfgang Goethe, Die Leiden des jungen Werthers (1774), um livro que os

\footnotetext{
3 "Widespread imitation of Werther's suicide was never conclusively demonstrated, but authorities were sufficiently apprehensive to ban the book in several areas, including Italy, Leipzig, and Copenhagen".
} 
críticos adoram resumir em poucas palavras: "é um romance sobre um amante nãocorrespondido que se mata”. No Brasil, de Otto Maria Carpeaux, nos anos 40, até um prefácio recente à tradução de Marcelo Backes, tende-se a acentuar o aspecto bombástico da recepção inicial do livro ou como artifício mercadológico, ou como uma tentativa algo romântica de atestar o poder da boa literatura sobre o comportamento humano, ou ainda como forma de resumo: quando historiadores da literatura alemã como Carpeaux falam do Sturm und Drang, uma espécie de vanguarda que existiu na Alemanha entre 1765 e 1785, eles preferem eleger Os Sofrimentos do jovem Werther como a manifestação mais paradigmática do espírito combativo do movimento, e deixam de falar de todos os outros livros publicados naqueles vinte anos, os quais hoje em dia quase ninguém mais lê (CARPEAUX, 2008, p. 1272 et seq).

E aqui começa a problematização que será desenvolvida neste artigo: na altura de 1774, quando da publicação do livro, associá-lo ao suicídio foi uma tentativa de contrapropaganda, veementemente combatida por Goethe ${ }^{4}$. Tampouco o livro é um elogio à atitude dos suicidas; até o fim de sua vida, seu autor afirmou que o público alemão não entendeu a motivação por trás da obra (como veremos adiante). Quando comentaristas atuais atribuem o suicídio de Werther à sua "unilateralidade trágica” (BACKES, 2012, p. 11) ou o consideram um resultado lógico da luta trágica que se instalou entre si e as normas de uma sociedade que o separava da mulher amada (POTTER, 2012, p. 134), estamos lidando com certa ingenuidade. O caso de Werther não é trágico, como se ele fosse o bode expiatório necessário numa configuração pré-determinada por uma força superior, o que acontece no caso da tragédia clássica: argumentaremos, pelo contrário, de que modo seu suicídio jamais será um ato heroico, devidamente trágico, por mais que esta seja sua intenção. Goethe parece alegar que mesmo uma atitude radical como a daqueles que abreviam a própria existência não lhes permite contornar a banalidade superlativa da vida moderna — esse é um romance sobre um mundo desencantado, e sobre a possibilidade de o indivíduo confrontar um tal desencanto.

\footnotetext{
${ }_{4}^{4}$ Os detalhes dos diversos processos de censura do livro estão bem resumidos em Wiethölter (2006, p. 909958).
} 


\section{Diferentes valores do suicídio em $\mathrm{Os}$ Sofrimentos do jovem Werther}

O roteiro d'Os Sofrimentos do jovem Werther pode ser resumido em poucas sentenças: Werther é um jovem jurista que resolve se mudar para o interior alemão em busca de uma vida nova. Não sabemos de fato o que o levou a migrar; o fato de o romance ser composto unicamente por cartas datadas, enviadas pelo protagonista para seu confidente Wilhelm, confronta-nos com um tempo narrativo exclusivamente focado no presente da enunciação. O que sabemos da vida de Werther é filtrado por seu estado de espírito no momento em que escreve cada uma das cartas; o trabalho do leitor se torna, assim, o de reorganizador dos fatos, além do de confidente indireto da personagem principal. Em sua nova vida, Werther goza de um breve período de bem-estar, para então se apaixonar por Lotte, uma local com gostos parecidos com os seus, mas que já está prometida para outro homem, o funcionário de governo Albert. Werther torna-se amigo dos dois, mas encara crescente dificuldade em esconder seus fortes sentimentos pela moça; daí decorrem diversas crises e surtos que terminarão em seu suicídio, no final do livro.

Um aspecto relevante sobre esse primeiro romance de Goethe para os estudos do suicídio é que as personagens do próprio livro dialogam a respeito do assunto, e não chegam a qualquer acordo acerca do seguinte dilema: que direito temos de tirar a própria vida? $\mathrm{Na}$ carta datada a 12 de agosto, Werther relata duas respostas possíveis para a questão, uma sua e outra de Albert, alguém que nessa altura do romance é tanto seu rival (noivo de Lotte) quanto colega de trabalho. "Não há dúvida de que Albert é o melhor homem da face da terra", Werther diz no início da carta (GOETHE, 2012, p. 66). E então conta sobre detalhes da visita que fez ao amigo; das pistolas que pediu para caçar e obteve sem grandes problemas. Enquanto manuseiam as armas, entremeia-se na cena uma anedota de Albert sobre a razão de evitar carregar pistolas consigo: conta que certa vez passou três meses na casa de campo de um conhecido e levou um par de tercerolas para se proteger de eventuais assaltos. $\mathrm{O}$ criado foi fazer uma brincadeira com a arma na frente da criada, a arma disparou e logo a precaução tornou-se arrependimento.

Werther interrompe o relato do discurso de Albert e só menciona quão enfadonho este pode se tornar quando começa a tagarelar sobre seus princípios; numa atitude juvenil, Werther leva uma das pistolas, descarregada, que tem em mãos às têmporas, como quem diz não estar mais suportando aquela conversa. Albert, então, fica extremamente ofendido por ao menos passar pela cabeça do amigo fazer um tipo de brincadeira tão vil; "não posso 
compreender como um homem poderá ser tão louco a ponto de se estourar os miolos [...]" (GOETHE, 2012, p. 67).

Nesse momento o conflito está instalado: Werther vocifera contra os juízos prontos de homens como Albert contra os loucos e desesperados, e apela que cada caso de suicídio é único e complexo demais para querermos desvalidá-los, a todos, como frutos da loucura: "Por acaso buscastes alguma vez [...] as íntimas circunstâncias de um ato? Sabeis precisar com certeza as razões por que ele ocorreu, por que ele teve de ocorrer? Se tivésseis feito isso não seríeis tão pronto em vossos juízos" (idem). Há certas circunstâncias que tornam o suicídio aceitável e até mesmo desejável, Werther argumenta retomando um princípio do estoicismo - é como se, tal qual filósofo da Antiguidade, ele assumisse a posição de homem sábio que contempla a realidade das paixões turbulentas dos homens comuns com distanciamento, sem se deixar ele próprio se perturbar por elas (CRITCHLEY, 2015a, p. 1). O protagonista desvia dos contra-argumentos de seu interlocutor como um jurista moderno que, no romance, de fato é; seu argumento retoma os principais pontos que serão formalizados mais tarde na teoria da imputação, a doutrina jurídica que ressalta a importância de analisar a intenção de um réu de causar danos a outrem, e não somente nos resultados finais de sua ação ${ }^{5}$. Na época de Goethe, em que a atual Alemanha era na realidade o Sacro Império Romano-Germânico e operava com base em doutrinas milenares do direito romano, a argumentação de Werther o revela como membro de uma vanguarda jurídica. Albert, por sua vez, não é nada além de um bom funcionário do governo: ele é 100\% dogmático. “Concordarás comigo [...] que certos atos são e continuarão sendo criminosos, sejam quais forem os motivos" (GOETHE, 2012, p. 68).

O protagonista, porém, não está interessado em uma discussão de aspectos técnicos do direito, como lemos adiante, mas unicamente em dar vazão a sua inclinação tácita ao suicídio. A discussão se torna calorosa, e Werther dá vazão à sua frustração com a injustiça do mundo: "Um povo que geme sob o jugo insuportável de um tirano, ousareis taxá-lo de fraco quando enfim se levanta e rompe os grilhões?" Ao que Albert responde: "Não me leve a mal, mas [o exemplo] que acabais de citar não parece aplicável a este caso" (GOETHE, 2012, p. 69). E Albert está meio certo, ainda que o esteja por não supor que o suicídio para Werther está próximo de um ato revolucionário, de protesto radical contra um mundo ruim:

\footnotetext{
5 A teoria da imputação ganhou reformulações diversas até o século XX, tanto no ramo do direito administrativo (no princípio de imputação volitiva de Otto Gierke) e do direito penal (no princípio de imputação objetiva de Karl Larenz e Claus Roxin).
} 
aqui entramos em contato com a primeira teoria, digamos, incipiente do ato suicida, como o protagonista a defende. Werther a complementa na famosa tese de que o suicídio é uma saída racional (e não passional) para uma vida desgraçada; remetendo à passagem do Evangelho de João, 11: 4, ele diz que o ato é a cura para uma "doença mortal" cuja cura é impossibilidade pela própria natureza. Notemos o trecho seguinte: “A Natureza não encontra nenhuma saída desse labirinto de forças intrincadas e antagônicas, e o homem tem de morrer" (ibidem, p. 72). Werther, falando como um homem do século XVIII treinado em retórica jurídica, certamente se vale da formulação para dar autoridade milenar e mística a seu discurso (já que os termos para "doença mortal”, Krankheit zum Tode, soava bastante antiquado já no alemão do século XVIII). Mas pensemos na dimensão semântica da construção: se estendermos a imagem evocada, o suicídio é uma saída para um mal que, tal qual um vírus, acomete certos indivíduos que têm o azar de estar no lugar errado, junto das pessoas erradas, e têm sua paz destruída.

Já temos aqui um ato de encenação, uma vez que tudo o que Werther conta — não ignoremos isto - insere-se em suas cartas íntimas ao amigo Wilhelm. No contexto da carta de 12 de agosto, ele supostamente relata palavra por palavra a discussão que teve com o rival amoroso e da qual, em sua opinião, saiu como vencedor. Nesse sentido é que pensamos a carta como encenação: ela dá mostras de sua liberalidade, sua negação ao dogmatismo e a uma filosofia fácil e não analisa motivos íntimos dos agentes morais, ao mesmo tempo em que revela a vaidade intelectual wertheriana. Ele tem controle absoluto de deliberar sobre a própria vida, até mesmo quanto à questão de tirá-la ou não. Isso nos prepara muito para o que acontecerá no final do romance, mas façamos um balanço do relato de 12 de agosto: simbolicamente, ele prova que Werther está conquistando pequenas vitórias sobre seu rival (embora não roube sua namorada), e que faz questão de reafirmá-las para si e para o amigo.

Tudo para Werther carrega um caráter simbólico, e essa é parte de seu problema: ele vive em um universo não-tátil, ocupa-se demais das possíveis ligações abstratas entre os signos que compõem o mundo e deixa de atuar diretamente na vida prática ${ }^{7}$. Aqui reside a

\footnotetext{
${ }^{6}$ Krankheit zum Tode na tradução de Lutero; “enfermidade para a morte” em tradução livre para o português. O termo é o mesmo que será desenvolvido por Kierkegaard para explicar seu conceito de desespero. Curiosamente, a passagem bíblica diz: "E Jesus, ouvindo isto, disse: Esta enfermidade não é para morte, mas para glória de Deus, para que o Filho de Deus seja glorificado por ela". Werther faz questão de invertê-la.

${ }_{7}$ Os exemplos são muitos. Na carta de 6 de setembro, por exemplo, o protagonista relata ter mandado fazer uma casaca azul igual a que usava quando dançou com Lotte pela primeira vez, torcendo para que a estime tanto quanto estimou a antiga casaca. Ela, porém, "não [o] satisfaz inteiramente" (GOETHE, 2012, p. 114). A tentativa de dotar plasticidade às representações simbólicas sempre se reverte em fracasso, mas Werther custa para aceitar a tarefa evidente de que símbolos não substituem objetos reais.
} 
crítica implícita a uma visão de mundo doentia que Goethe, trinta anos mais tarde, identificará como a visão de mundo romântica. As pistolas que ocupam o protagonista no início da carta de 12 de agosto, por exemplo, serão as mesmas que ele pedirá emprestadas no final do romance - sob o pretexto de querer ir à caça (ver ibidem, p. 165, 168) - e com uma das quais dará um tiro na própria cabeça. É como se ele quisesse dizer a Albert: ‘eu, o sujeito absoluto, transcendente a toda sorte de valores normativos, venci'.

Aqui reside um misto paradoxal entre baixa autoestima e extravagância vaidosa dos suicidas, algo que Goethe captou de modo brilhante no romance: "suicidas [...] desafiam a intransitividade da morte ao se transformarem nos sujeitos (ativo) e nos objetos (passivo) da autodestruição" (LOMAN, 2012, p. 96). São eles que estão sob controle, e isso lhes garante uma forma superior de liberdade: a liberdade de identificar as amarras da vida, e de (supor) poder transcendê-las. Podemos identificar metáforas relativas a liberdade, prisão, limitação, sufocamento, voo, mergulho, no discurso posterior do protagonista (todos os grifos são meus):

Quando penso nos limites [Einschränkungen $=$ mordaças, restrições] que circunscrevem as ativas e investigativas faculdades humanas [...] emudeço (carta de 22 de maio, GOETHE, 2012, p. 24, trecho corrigido com base no original).

Ah, por quantas vezes desejei então ter as asas do grou que passava acima da minha cabeça, voar às praias do mar imenso, beber a vida na taça espumante do infinito [...]! (18 de agosto, GOETHE, 2012, p. 75).

Morrer! O que é que isso significa! Vê, nós sonhamos quando falamos da morte. Vi morrer muitas pessoas, mas o homem é tão limitado que não faz nenhuma ideia do começo e do fim de sua própria existência. [...] Sepultado num pedaço de terra fria, tão estreito, tão escuro! (O editor ao leitor, GOETHE, 2012, p. 163).

Como me acorrentei a ti [Lotte]! Desde o primeiro instante não podia deixarte mais! ... aquele laço deve ser enterrado comigo, tu mo presenteaste no dia de meu aniversário! (O editor ao leitor, GOETHE, 2012, p. 172).

Os exemplos são muitos. Em todos os trechos supracitados, Werther está preso em sua reflexão ou na fantasia mais desvairada; não é possível expressar sua ânsia pelo infinito e absoluto observando o mundo empírico a seu redor. Por esse motivo, as descrições das cenas comuns da vida tornam-se cada vez mais tingidas pela imaginação; isso impede ao protagonista de relativizar suas afecções imediatas. Ele se torna progressivamente controlado pela sua sentimentalidade, ao ponto de afirmar: "Meto-me dentro de mim mesmo e acho aí um mundo!" (22 de maio, GOETHE, 2012, p. 22). 
A frase merece alguma atenção, visto que se localiza no início do romance, mas resume bem o equívoco que guiará o protagonista à morte. Uma tradução mais correta diria que, ao ver-se perante uma dificuldade, ele se volta para dentro de si [kehrt zu sich selbst], como quem regressa, quem se ausenta do mundo em rumo à solidão anuladora do para-si, de seu ego. Paradoxalmente, ao fazê-lo, Werther afirma encontrar ali um mundo: o que mostra sua ignorância filosófica de que o mundo é necessariamente um espaço de câmbios intersubjetivos, de abertura ao acaso e de submissão por forças exteriores maiores que o sujeito. Além disso, como muitos suicidas, Werther supõe-se controlador das forças atuantes sobre seus afetos, como se fosse, tal qual um ego absolutamente autônomo, uma entidade desvinculada daquele corpo que sente e sofre. É como quem diz: “eu, que neste momento decido me matar, chego a uma conclusão racional sobre a impossibilidade de continuar vivendo. Cheguei a essa conclusão por ter consciência do sofrimento que meu Eu-sentiente, sofrendo há tanto tempo, me comunicou".

Lembremos que a divisão entre $(A)$ um ego abstrato onde reside o núcleo duro e profundo do $\mathrm{Eu}$, e (B) um Eu-sentiente, mundano e afetado pela bioquímica cerebral, foi uma perspectiva filosófica amplamente aceita pelo menos de Descartes a Leibniz, até que Kant reservou ao ego (a tal unidade transcendental de apercepção) um número limitado de juízos possíveis (os seus famosos juízos a priori; ver KANT, 1974, p. 160-163). Aqui temos abertura para uma antropologia filosófica que pensa o ser humano como construído por experiências, como sempre incompleto e desvinculado de um suposto repertório de verdades-em-si; a desconfiança moderna perante o sujeito e sua vida psíquica encontra sua gênese neste ponto. Todavia - e isso é um dado de suma importância para a história do pensamento ocidental - Kant só o fez em 1781, com o lançamento da primeira edição da Crítica da Razão Pura; há algo de visionário em Os sofrimentos do jovem Werther e sua incipiente teoria do ser no que ele propõe a visão da autonomia radical da subjetividade como um erro grosseiro — não um erro metafísico, como propõe Kant, o qual gera de ideias puras da razão, mas um passo em falso existencial, particularmente perigoso para sujeitos mais sensíveis como Werther, que poderiam ser salvos com ajuda de entes queridos e de socialização.

Voltando à primeira discussão sobre a dignidade dos suicidas (carta de 12 de agosto), Albert tem bastante razão ao identificar um paradoxo no discurso de seu interlocutor. Observemos o quadro pintado por Werther:

Olha para o homem em sua limitação e vê como as impressões atuam nele, como as ideias se fixam nele, até que enfim a paixão sempre crescente o 
priva de toda a força de vontade e o lança ao solo. Em vão o homem ajuizado [i.e. alguém como Albert] e razoável contemplará o estado do infeliz, em vão lhe dará seus conselhos! (ibidem, p. 70).

É como quem diz: ninguém mentalmente são poderá ajudar um suicida, da mesma forma que alguém são é incapaz de curar um tuberculoso sussurrando-lhe conselhos. Um homem, por mais racional e são que seja, não é autoridade para desviar um suicida convicto de seus propósitos, uma vez que desconhece todo o contexto vivido por este.

Mas porque o próprio suicida seria um agente capaz de confirmar a necessidade de sua expiação? Werther sente o paradoxo de sua postura em momentos esparsos pelo texto. O que parece mais icônico é aquele narrado na carta de 13 de maio, quando começa a sentirse sufocado por seu próprio ego e sentimentos, e passa a evitar quaisquer estímulos intelectuais capaz de desgastá-lo. No contexto, Wilhelm supostamente o questiona se deveria enviar livros ao amigo, ao que este responde:

Tu perguntas se deves enviar-me os meus livros... Meu caro, te peço pelo amor de Deus, deixa-os longe do meu pescoço. Não quero mais ser guiado, animado e afogueado... Este coração já fermenta o bastante por si próprio. [...] Tu sabes que não existe no mundo nada tão instável, tão inquieto quanto este coração (GOETHE, 2012, p. 17).

O próximo passo é evitar a companhia dos outros; num gesto bastante rousseauniano, Werther passa a dividir as pessoas ao seu redor entre pertencentes ao "mundo da civilização" (GOETHE, 2012, p. 18) e a gente simples, camponesa, e mais próxima da natureza. Interessantemente, Lotte só aparecerá no romance na carta de 16 de junho (GOETHE, 2012, p. 32) — mas, como vimos até então, toda uma visão de mundo problemática já está bem expressa no livro. Assim, é de se esperar que a relação de Werther com o casal de noivos Lotte e Albert acabe da forma que acabou. Seu problema não é amor não-correspondido, propriamente, mas uma expectativa equivocada em relação a seu ego. Esse ego logicamente só encontraria amarras dentro da província alemã de meados de 1770, no momento em que ele tem de lidar com uma moça simples, órfã de mãe e prometida em casamento ao funcionário do governo Albert, o qual, no momento em que se insere na história contradiz as projeções de Werther, e o leva a afirmar resignadamente: "Albert chegou, e eu irei embora". O indivíduo autossuficiente é destronado pela realidade (carta de 30 de julho, GOETHE, 2012, p. 84). 


\section{A estetização da morte: o suicídio como ato literário}

A próxima manobra do protagonista é reinterpretar sua vida sob a perspectiva da morte. Num gesto que mistura narcisismo e desprezo por si próprio, Werther busca aniquilar seu corpo ao mesmo tempo que fantasia com a forma que entes queridos verão sua morte. "Dirás a minha mãe que reze pelo seu filho, e que lhe peço perdão por todas as mágoas que tenho lhe causado" (GOETHE, 2012, p. 143), ele diz na carta de 20 de dezembro. "Era meu destino atormentar as pessoas às quais só devo alegria” (GOETHE, 2012, p. 143-144). O termo "destino" é central aqui, e começa a abundar em seu discurso; se no livro 1 há quatro ocorrências do termo, no livro 2 elas sobem para nove.

A noção de destino em questão pode ser vista como parte essencial da lógica suicida do jovem; vendo seu princípio de autonomia radical refutado pelo mundo exterior, surge a tendência de Werther encarar a própria vida como uma história de martírio. Ele se força a entendê-la como uma narrativa de caráter poético que, se for lida de acordo com suas intenções autorais, servirá como exemplo de resistência a um mundo cruel em que nobres desprezam os pobres, em que a mulher supostamente destinada a se casar com ele foi prometida a outro homem economicamente mais promissor, etc. Notemos o tom de sua carta de suicídio: “Quando ser enterrado nestas roupas, Carlota, tu as tocaste, santificaste-as [...] oh, beija-os [seus irmãos] e conta-lhes o destino de seu desgraçado amigo. Oh, os queridos!” (GOETHE, 2012, p. 172). Os irmãos de Lotte, todos crianças, cumprem o papel das gerações vindouras que conheceram o suicida em vida e por ele foram amadas; está nas mãos deles mantê-lo na memória, elevando-o a um ícone da resistência. Um dado paradoxal deriva daí: o valor de Werther como ícone da resistência só se completaria uma vez que ele estivesse morto. $\mathrm{O}$ valor de sua vida é constante e duradouro, mas só começa a ter validade uma vez que uma tal vida acabe.

O suicídio de Werther não é um caso único no sentido de ser formulado tal qual um ato literário, como Loman (2012) o descreveu: todos os casos de suicídio estudados pela autora têm como elementos constitutivos um interesse sistemático do suicida de se inscrever e encenar o sentido de sua individualidade no mundo. A carta de suicídio forma uma cena de expiação que nós, os vivos que restamos para lê-la, tentamos reconstruir como quem investiga uma cena de crime, recuperando as motivações e últimos momentos da vida do suicida. "Como evento literário, ela é a própria possibilidade de ficção, a morte tornada ficção e reencenada, como espetáculo e sacrifício, diante de cada leitor, sua audiência póstuma" 
(LOMAN, 2012, p. 102). Em partes é isso que o editor ficcional d'Os sofrimentos do jovem Werther faz numa seção final do livro intitulada "O Editor ao Leitor", convidando que o leitor acompanhe sua narrativa com empatia (GOETHE, 2012, p. 133 et seq). Na descrição da cena de suicídio, lemos: "Estava estendido perto da janela imóvel e de costas, todo vestido e calçado, de casaca azul e colete amarelo. [...] Do vinho bebera apenas um copo. Emilia Galotti jazia aberta sobre a secretária” (GOETHE, 2012, p. 173).

Tudo é muito bem ensaiado: Werther escolhe uma vestimenta minimamente excêntrica para a época, capaz de marcar sua personalidade e estilo, bebe um cálice de vinho simulando Jesus na última Ceia (ainda que não o faça cercado de discípulos, mas isolado em seu quarto; ver descrição da cena em Lucas 22). E, por fim, deixa uma edição da famosa tragédia burguesa de Lessing, Emilia Galotti (1772) em destaque, como quem quer forçar uma relação entre sua própria história de vida com um roteiro ficcional. Tudo carrega uma intenção explícita: “O caráter literário do texto está inscrito no lado do objeto intencional [...] Há 'dentro' do texto aspectos que apelam por uma leitura literária e fazem lembrar a convenção, instituição e história da literatura" (DERRIDA, 1992, p. 44-45) ${ }^{8}$. O ato derradeiro mostra o ápice da loucura wertheriana, uma que se ensaia no início da narrativa quando ele confunde os limites entre ficção e realidade, intenção e efetividade.

Consideremos uma segunda marca textual que valida a tese de Loman do suicídio como ato literário. Mencionou-se acima o termo "martírio", algo que nos remete ao gênero literário da hagiologia, da descrição da vida dos santos e santas. Essa comparação não é tão disparatada quanto à primeira vista pode parecer. No próprio título do romance, assim como em trechos que trataremos a seguir, Goethe nos conduz por caminhos interpretativos que, de forma quase herética, relacionam Werther aos santos. Na recepção inicial da edição de 1774, foi justamente este o primeiro aspecto criticado na obra, mais do que o tema do suicídio em si. Intitulá-la Os sofrimentos [Leiden] do jovem Werther era provocativo por ser parecido demais com a tradução luterana d'a Paixão de Cristo [die Leiden Christi] ou das histórias das vidas de santos. É impossível sondarmos se a intenção de Goethe foi de fato provocar as autoridades eclesiásticas; o que é certo é que, se este foi o caso, ele obteve sucesso em fazêlo ${ }^{9}$ Igualmente, desde a capa do livro há uma sugestão de que um jovem suicida anônimo

8 "The literarity of the text is inscribed on the side of the intentional object (...). There are "in" the text features which call for the literary reading and recall the convention, institution, or history of literature". A tradução é de Lilia Loman (2012, p. 101, nota 4).

${ }^{9}$ Ver Wiethölter (2006, p. 940), além das resenhas de Christian Garve, Johann Melchior Goeze, Christoph Heinrich Hölthy, Homius, Balle \& Jansen em Rothmann (1987, p. 131; 135-140). 
foi elevado ao estatuto de santidade — seja porque ele de fato o adquiriu, tornando-se um ícone modelar, ou, o que parece mais coerente, porque parte das ilusões de Werther era imaginar que sua existência possuía um valor exógeno. Que seria lembrado como um santo é lembrado e preenche as preces dos fiéis. Werther, em outras palavras, é obcecado com sua própria imagem.

Para suportar uma tal interpretação, consideremos um dos últimos relatos que ele deixa a Lotte (e, o que é importante: em uma carta nunca enviada, encontrada junto de seus papeis): “Ah, quereria que me enterrásseis à beira de um caminho, ou num vale solitário, a fim de que pastores e levitas, passando junto a meu túmulo, levantassem as mãos ao céu abençoando, e o Samaritano vertesse uma lágrima por mim" (GOETHE, 2012, p. 171). O trecho indica uma falta de contato com a realidade em mais de um aspecto. Não só na pretensão por santidade que se observou acima, como também nas referências à geografia do Velho Testamento: os levitas desapareceram da narrativa bíblica assim que Nabucodonosor da Babilônia (634 AEC - 562 AEC) conquistou Judá. Os samaritanos são um grupo étnico ainda existente hoje, mas que se encontra espalhado por Israel e Palestina. Certamente não pelo interior alemão. Werther vive como quem já fez sua despedida da empiria, desistindo de toda a lógica e observação. É como se ele se tornasse puro símbolo, pura alma, a ponto de fantasiar uma união espiritual (mas sugestivamente erótica) com Lotte no pós-morte:

Vou ter com meu pai, com o teu pai. Queixar-me-ei a ele, e ele haverá de me consolar até a tua chegada [i.e. a chegada de Lotte ao céu], quando voarei ao teu encontro, cingir-te-ei, ficando unido a ti em presença do Eterno, num abraço infinito (GOETHE, 2012, p. 165).

Há um caráter sugestivamente literário, num sentido amplo da palavra, na narrativa que Werther conta para si mesmo sobre a suposta tragédia de sua vida ${ }^{10}$. Assumindo que haja uma força superior capaz de determinar os eventos responsáveis pela abreviação de sua existência, (seja ela justa ou não), Werther está mostrando ser capaz de dar um tiro na cabeça, mas jamais abrir mão da crença num significado inerente a sua existência singular, radicalmente autônoma. Se há algo de "trágico" em sua vida — num sentido menos técnicoliterário, mais ligado ao senso-comum — é o fato de ele esperar assumir um valor de ícone

\footnotetext{
${ }^{10}$ É digno de nota que os termos Tragödie, Trauerspiel, tragisch, etc. não aparecem uma única vez no texto. É como se o protagonista tivesse importado um formato de roteiro, ou de dinâmica textual, de uma tradição milenar para pensar a própria existência, mas estivesse semi-inconsciente do fato. Reconhecê-lo seria ter que admitir a artificialidade de suas motivações, destruir a justificativa que encontrou, na altura do livro II, para se matar.
} 
matando-se, e não conseguindo absolutamente nada. Werther, como todos os homens, está condenado ao desamparo transcendental, para usarmos a formulação de Lukács: sua vida termina com o tiro na cabeça, e todo seu investimento numa imagem póstuma de si foge-lhe do controle. Esta, portanto, não é uma tragédia no sentido estrito do termo, mas uma recaída na banalidade não muito diferente do tipo de vida contra a qual ele resiste.

Voltemos com a fortuna crítica de Goethe mencionada no início deste texto: comentaristas ainda atribuem ao suicídio de Werther um tom trágico e expiatório (BACKES, 2012), como se o fato de sua história estar escrita o erguesse à condição de herói trágico da modernidade, "festejado como um defensor incondicional de reivindicações que, em nome da natureza e dos ideais de virtude a ela ligados, causaram uma reviravolta na [dinâmica de] socialização" de sua época (WIETHÖLTER, 2006, p. 940) ${ }^{11}$. Que precisou morrer para que algumas críticas à socialização do mundo burguês fossem veiculadas devidamente. Já em 1775 Goethe tinha consciência de casos de suicídio decorrentes da leitura de seu livreto; isso é algo que lhe causou uma extrema perturbação e revolta contra o público (ROTHMANN, 1987, p. 151). A recepção do livreto, em resumo, foi equivocada; a criação fugira do controle de seu criador ${ }^{12}$. Tendo isso em vista, na primeira reimpressão em Leipzig, fez-se uma adição. Já na capa o autor inseriu uma advertência em versos cujo quarteto final diz:

Tu o choras, dizes amá-lo, alma querida, E salvas da vergonha a sua memória;

Vê, seu espírito te acena da ermida; Sê homem e não segue a mesma história (GOETHE, 2012, p. 176).

Os termos são cuidadosamente selecionados: Goethe aproveita a fantasia de Werther de virar um fantasma, um modelo para as gerações vindouras, e assume um leitor comovido por sua história (“Tu o choras...”). Após ler a obra, o leitor ficcional se vê na necessidade de salvar a memória do jovem suicida, livrando-a da vergonha pública (e, note, não a santificando ou se valendo de seu modelo). Do cemitério, o Werther-fantasma acena e ordena que o leitor não siga seu exemplo e seja o homem que ele próprio não foi. A tradução não abarca a semântica do termo utilizado no original para designar de onde Werther transmite sua mensagem derradeira: aus seiner Höble, da vala aberta em que suicidas eram jogados, fora do solo de cemitérios cristãos. Ermida, uma pequena capela situada numa região afastada, dá justamente a impressão oposta. Se seguirmos o imaginário cristão que

\footnotetext{
11 "[Werther wurde als] bedingungsloser Verfechter der Ansprüche gefeiert, die namens der Natur und der ihr abgewonnenen Tugendideale im Zuge der [...] Sozialisation [...] im Umlauf gebracht worden waren“.

${ }^{12}$ Goethe expressou essa convicção até uma idade avançada. Ver documentação extensa em Wiethölter (2006, p. 916).
} 
determinava a vida e morte dos indivíduos na Alemanha do século XVIII, podemos adicionar: em vez de ser louvado como mártir, Werther é destinado a ser jogado numa vala qualquer, como um animal. "Nenhum sacerdote o acompanhou", é a frase final do texto (GOETHE, 2012, p. 174).

\section{Revisitando o tema do suicídio: socialização como cura da "doença mortal”}

Os sofrimentos do jovem Werther terminam com o enterro do protagonista, omitindo detalhes importantes sobre o efeito de seu suicídio sobre entes queridos. De fato, o emudecimento do narrador a esse respeito é deliberado: "da comoção de Alberto, do desespero de Carlota não consigo dizer nada" (GOETHE, 2012, p. 173). Podemos supor manifestações de revolta e culpa por parte dos envolvidos na narrativa, mas o desfecho do romance cria um efeito de vazio, uma lacuna perturbadora.

De um lado, a recepção polêmica, os suicídios decorrentes da leitura, a febre wertheriana que levava jovens a se vestirem como o suposto herói suicida; de outro, a recepção favorável da crítica marxista (Mehring, Lukács), a ligação de Werther à resistência contra a sociedade estamental — toda essa variedade de reações possíveis ao texto parece derivar de sua natureza lacunar. O velho Goethe, já sessenta anos após a escrita de seu primeiro romance, justificou a escrita do romance de juventude em uma conversa relatada por Riemer: havia um taedium vitae generalizado na época e que gerava ocasionais suicídios, e a necessidade de problematizar esse fato gerou o romance de 1774 (GOETHE, 2004, p. 172, conversa de data desconhecida, entre 1804 e 1812). Não havia qualquer interesse de louvar ou censurar o suicídio, somente o de tratá-lo como um fato da vida social alemã daquela época.

Mas o texto fugiu ao controle de seu criador, o que prova a autonomia da obra de arte, sobretudo de um romance com valor artístico, gênero que só então começava a ser levado a sério pelo establishment literário. Ocasionalmente, Goethe voltou a tratar do tema do suicídio, da "enfermidade para a morte" da qual fala Werther, num romance posterior, Wilhelm Meisters Lehrjahre [Os anos de aprendizado de Wilhelm Meister, 1795/1796]. Em seu livro 1, o protagonista Wilhelm passa por experiências paralelas às de Werther: ele sai da casa dos pais, começa a concretizar planos pessoais, tem os primeiros contatos com mulheres e, por fim, se apaixona por uma mulher quase inacessível, Mariane, uma atriz muito mais 
experiente do que ele. Os dois começam a ter um relacionamento amoroso que dura alguns meses. O livro 1 fecha com Wilhelm presenciando uma cena que, a seu ver, seria prova concreta da traição de Mariane.

Aqui entra o avanço da discussão nos romances de Goethe. Wilhelm não se mata. O narrador conta como, com a ajuda do cunhado e da irmã, o protagonista aos poucos se recupera da doença mortal: "Saltaremos [...] alguns anos e iremos procurá-lo somente ali, onde esperamos reencontrá-lo numa espécie de atividade e prazer, relatando por ora apenas o necessário para a continuidade da história” (GOETHE, 2006, p. 87). O detalhe é importante: só há algo a se contar a respeito dos anos de aprendizado (não mais de sofrimentos) a partir do momento em que o protagonista se livra de sua postura existencial ensimesmada, fadada ao fracasso. Wilhelm Meister ultrapassa uma fase de autocomiseração, em que se censura "amargamente por ainda ter, depois de uma tão grande perda, um instante sem dor, tranquilo, indiferente" (GOETHE, 2006, p. 88-89). Aquela mistura de obsessão com certa autoimagem e ódio contra si é a mesma de Werther.

A virada em sua trajetória se dá por um misto de sociabilidade e força de vontade para questionar suas ideias. Mais uma vez como em Werther, o conceito de destino precisa ser refutado para que haja cura. "Wilhelm seguiu vivendo laboriosamente, convencido de que o destino lhe havia preparado aquela dura prova para seu próprio bem [...] Por mais determinado que estivesse a renunciar a suas mais caras ideias, foi necessário, contudo, algum tempo para se convencer plenamente de seu infortúnio” (GOETHE, 2006, p. 90, meu grifo). A vida ativa, o contato com novas realidades e pessoas, possibilita a cura. $\mathrm{O}$ suicídio perde o sentido uma vez que é revelado como "uma solução definitiva para um problema temporário", como Critchley (2015b) formula magistralmente.

A partir do capítulo 3 do livro II (GOETHE, 2006, p. 96 et seq), o romance vira algo bastante diferente: ele se torna um romance de formação, da construção do indivíduo através de encontros intersubjetivos. Os sofrimentos do jovem Werther, em contrapartida, foi um romance de deformação, da ilustração de um caminho em falso que tornava impossível o heroísmo na vida moderna. Diferente do que ocorre nesta obra, Wilhelm Meister aprende a praticar uma doutrina do amor fati, de aceitação dos fatos da vida, formulada posteriormente por Nietzsche, o grande herdeiro no século XIX da teoria do ser de Goethe. A ansiedade metafísica por fórmulas que preencham o indivíduo existencialmente é reconhecida como 
um déficit da cultura e psicologia humanas, uma abordagem já presente na história do pensamento ocidental desde a primeira metade do século XVIII ${ }^{13}$.

A inversão proposta por Critchley (2015b, numa leitura de Emil Cioran) é uma que diz: no fundo, suicidas são grandes otimistas. Visitar a possibilidade de se autodestruir é um fato humano; não há redenção da condição humana sem que isso ocorra uma porção de vezes. Mas ir até o fim — diz Cioran — é um ato de desespero por um sentido pleno na vida. É crer que me destruindo eu terei minha vingança perfeita, ou encontrarei finalmente meu lugar (como Werther), ou que solucionarei de fato um problema amoroso (como Wilhelm).

O fato de o romance epistolar sobre o suicídio ser reformulado e revertido em um romance de formação, numa narrativa que descreve a conquista de espaço no mundo via socialização e formação de vínculos intersubjetivos, é de grande importância. Esse movimento revela uma tentativa por parte de Goethe de combater uma cultura obcecada por autoimagem, já em formação em sua época e em plena vigência nos dias atuais, propondo a noção de que o sujeito não pode existir sem o mundo exterior. Seja lá o que meu Eu (self) for — resume Critchley (2015a, p. 9), ecoando Goethe, "ele é algo só parcialmente meu, e igualmente parcialmente compartilhado com os outros. Se o direito ao suicídio emana de alguma ideia de propriedade de si, então eu estaria inclinado a dizer que não somos donos de nós mesmos" ${ }^{\prime 14}$. Aqui reside o grande argumento contra um suposto heroísmo dos suicidas; ele é falacioso uma vez que não existe heroísmo puramente individual.

\section{Referências}

BACKES, Marcelo. Prefácio. In: GOETHE, Johann Wolfgang. Os sofrimentos do jovem Werther. Porto Alegre: LP\&M, 2012, p. 7-12.

CARPEAX, Otto Maria. História da literatura ocidental. Volume II. Brasília: Senado Federal, 2008.

\footnotetext{
${ }^{13}$ Critchley (2015a, p. 1-3) identifica no filósofo bastante obscuro Radicati o início da ideia de que o cristianismo inculcou um medo irracional da morte e da vida na cultura. A teoria do ser de Goethe e Nietzsche podem ser vistas como tentativas de criar uma cultura do ser baseada na vida prática, avessa às abstrações que furtam qualidade à existência humana.

14 "Whatever my self may be, it is something that is partially my own, but also partially shared with others [...] If the right to suicide flows from some idea of self-ownership, then I would be inclined to say that we do not own ourselves".
} 
CRITCHLEY, Simon. Notes on Suicide (2015a). Unipa. Disponível em: $<$ https://www.unipa.it/dipartimenti/cultureesocieta/.content/documenti/relazionisummer-school/Critchley.pdf>. Acesso em: 15 de Nov. 2017.

Suicide (2015b). Institute for critical social inquiry. New School for Social Research. Aula pública. Disponível em: $<$ https://www.youtube.com/watch?v=ID3NaFds2QQ\&t=3988s >. Acesso em: 18 de Nov. 2017.

DERRIDA, Jacques. Acts of literature. London; New York: Routledge, 1992.

DEVIT'T, Patrick. 13 Reasons Why and Suicide Contagion. Scientific American, 8 de Maio 2017. Disponível em: <https://www.scientificamerican.com/article/13-reasons-whyand-suicide-contagion1/>. Acesso em: 06 de Nov. 2017.

GOETHE, J. W. Goethe: Briefe, Tagebücher, Gespräche. Gespräche, Band. 8. In: Digitale Bibliothek. Berlin: Directmedia Publishing, 2004.

Os anos de aprendizado de Wilhelm Meister. Trad. Nicolino Simone Neto. São Paulo: Editora 34, 2006.

2012.

Os sofrimentos do jovem Werther. Trad. Marcelo Backes. Porto Alegre: LP\&M,

KANT, Immanuel. Kritik der reinen Vernunft. Band 1. Frankfurt am Main: Suhrkamp Verlag, 1974.

KUNCZIK, Michael; ZIPFEL, Astrid. Gewalt und medien - ein studienhandbuch. Wien; Weimar; Köln: UTB - Böhlau: 2006.

LOMAN, L. O suicídio como evento literário. Revista Cerrados v. 21, n 33. Brasília: UnB, 2012, p. 93-103.

PHILLIPS, David P. The influence of suggestion on suicide: substantive and theoretical implications of the Werther Effect. American Sociological Review n 39, 1974, p. 340 354.

POTTER, Edward T. Hypochondria, onanism, and reading in Goethe's Werther. Goethe Jahrbuch no 19, 2012, p. 117-142.

ROTHMANN, Kurt. Johann Wolfgang Goethe. Die Leiden des jungen Werther: Erläuterungen und Dokumente. Stuttgart: Philipp Reclam, 1987.

WIETHÖLTER, Waltraud. Kommentar. In: GOETHE, Johann Wolfgang. Die Leiden des jungen Werthers - Die Wahlverwandtschaften - Kleine Prosa - Epen. Frankfurt am Main: Deutscher Klassiker Verlag, 2006, p. 907-1242. 


\section{Abstract}

The sorrows of Young Werther (1774) by Goethe was a pioneer in its portrayal of the mental decline of a young suicidal in a non-moralistic key. Read as a praise of suicide, it influenced some readers to take their own lives. We analyze how such a resolution goes against the story's ultimate message and do so, through close reading, by isolating central scenes where the characters discuss the issue. Instead of a heroic act, suicide stems from the polarization of the ego and a philosophical comprehension of man as a non-social being that, for Goethe, is the symptom of the culture of individualism.

Keywords: Goethe. Suicide. Werther Effect. Sturm und Drang

Recebido em: 18/06/2018.

Aceito em: 29/06/2018. 